\title{
Effect of Nanoclay Addition on the Morphology, Fiber Size Distribution and Pore Size of Electrospun Polyvinylpyrrolidone (PVP) Composite Fibers for Air Filter Applications
}

\author{
Iman Azarian Borojeni ${ }^{1}$, Arash Jenab ${ }^{2}$, Mehdi Sanjari ${ }^{3}$, Charles Boudreault $^{3}$, Michael Klinck ${ }^{2}$, Scott Strong ${ }^{2}$ \\ and A. Reza Riahi ${ }^{1, *}$ \\ 1 Department of Mechanical, Automotive, and Materials Engineering, University of Windsor, \\ Windsor, ON N9B 3P4, Canada; azarian@uwindsor.ca \\ 2 River Drive Manufacturing, Oakville, ON L6M 2Y1, Canada; arash@river-drive.com (A.J.); \\ mklinck@river-drive.com (M.K.); sstrong@river-drive.com (S.S.) \\ 3 NanoPhyll Inc., Montreal, QC H4S 2A4, Canada; mehdi@nanophyll.com (M.S.); charles@nanophyll.com (C.B.) \\ * Correspondence: ariahi@uwindsor.ca
}

check for

updates

Citation: Borojeni, I.A.; Jenab, A.; Sanjari, M.; Boudreault, C.; Klinck, M.; Strong, S.; Riahi, A.R. Effect of Nanoclay Addition on the Morphology, Fiber Size Distribution and Pore Size of Electrospun Polyvinylpyrrolidone (PVP) Composite Fibers for Air Filter Applications. Fibers 2021, 9, 48. https://doi.org/10.3390/fib9080048

Academic Editor: Martin J. D. Clift

Received: 31 May 2021

Accepted: 20 July 2021

Published: 1 August 2021

Publisher's Note: MDPI stays neutral with regard to jurisdictional claims in published maps and institutional affiliations.

Copyright: (c) 2021 by the authors. Licensee MDPI, Basel, Switzerland. This article is an open access article distributed under the terms and conditions of the Creative Commons Attribution (CC BY) license (https:// creativecommons.org/licenses/by/ $4.0 /)$.

\begin{abstract}
The fabrication of Polyvinylpyrrolidone (PVP) electrospun layers for air filter applications is the target of this study. Solutions of $10 \%$ PVP containing $0,3,10$ and $25 \mathrm{wt} \%$ nanoclay were used to fabricate electrospun fibers. Scanning electron microscopy showed that the fibers' roughness increased by increasing the nanoclay content, and it was maximum at the nanoclay concentration of $25 \mathrm{wt} \%$. Concurrently, nanoclay decreased the pore size considerably and increased the range of the fibers' size distribution up to $100 \%$. In addition, as the nanoclay concentration increased, the frequency distribution decreased abruptly for the larger fiber sizes and increased dramatically for the small fiber sizes. This phenomenon was correlated to the effect of nanoclay concentration on the conductivity of the solution. The solution's conductivity increased from $1.7 \pm 0.05 \mu \mathrm{S} / \mathrm{cm}$ for the PVP solution without nanoclay to $62.7 \pm 0.19 \mu \mathrm{S} / \mathrm{cm}$ for the solution containing $25 \mathrm{wt} \%$ nanoclay and destabilized the electrospun jet, increasing the range of fiber size distribution. Therefore, the PVP solution containing $25 \mathrm{wt} \%$ nanoclay has potential characteristics suitable for air-filter applications, owing to its rougher fibers and combination of fine and thicker fibers.
\end{abstract}

Keywords: nanofibers; electrospinning; nanoclay; Polyvinylpyrrolidone (PVP); air-filter

\section{Introduction}

Removing hazardous particles and aerosols from the air is in great demand in the world. Particulate matter such as mineral powder, carbon powder and bioaerosols, which may contain harmful micro-organisms such as bacteria and viruses, can cause acute and chronic diseases alike [1]. Many techniques have been developed for air purification, such as ionizers, ozonizers, photocatalytic oxidation and adsorption. However, filtration has been preferred in many cases due to its high efficiency and excellent stability [1,2]. There are three major categories of filters, namely non-woven, woven and membrane filters. Non-woven filters have the advantages of higher permeability, higher specific surface area, smaller pore size and controllable pore size distribution over woven filters, leading to higher filtration efficiency and lower pressure drop [3]. Methods such as spunbond and melt-blown have been commercialized to produce non-woven air filters. Nevertheless, they can only provide relatively thick fibers with low filtering efficiency for small airborne particles $(0.1$ to $0.5 \mu \mathrm{m})$ [1]. One of the most promising methods for the fabrication of nano-size fibers is electrospinning. A polymer solution or molten polymer is charged up by a high voltage power supply in this method. When the accumulated charge is above a critical value, the surface charge offsets the liquid's surface tension (polymer solution or molten polymer) and generates a liquid jet [4]. The jet stretches and whips rapidly due to 
its high residual surface charge and perturbation effect, leading to a dramatic reduction of its diameter before it reaches the collector [5]. A porous non-woven layer will be deposited on the collector by selecting proper electrospinning parameters, containing very thin fibers in the range of a few nanometers to $2 \mu \mathrm{m}$. Therefore, it improves the fine airborne particles' capturing efficiency to smaller than $0.3 \mu \mathrm{m}$ [6].

One of the advantages of electrospinning is controlling the morphology of fibers to improve the performance of the air filter and the pore diameters [7] and generating beads mixed with fibers to decrease the packing density and reduce the pressure drop [8]. Producing a wide range of fiber-size filters has also been suggested to increase filtering efficiency at low pressure drop [9]. Wang et al. [10] added silica nanoparticles to polyacrylonitrile (PAN) to fabricate a hybrid nanocomposite air filter with higher roughness of fibers. By increasing the fiber's roughness, slow air mobility regions (stagnation) near the rough fibers were developed when the electrospun layer worked as the air filter. Therefore, the capturing efficiency was enhanced significantly $(99.989 \%)$ while the pressure drop remained relatively low (117 Pa).

Polyvinylpyrrolidone (PVP) is a known biocompatible and biodegradable polymer with low toxicity [11], widely used in the medical, food, and cosmetic industries [12]. However, the water solubility of PVP is pointed out for air filter applications, especially in high humidity conditions $[13,14]$. There are reports that the water solubility of PVP has been used to trap micro-organisms by PVP air filter and extract them by dissolving the filter in the water $[14,15]$. However, for air filter applications, a crosslinking treatment is needed to limit the water solubility of PVP. Melike et al. have fabricated centrifugally spun PVP nanofibers for air filter application, which showed a high filtering efficiency and quality factor of $99.995 \%$ and $0.39\left(\mathrm{~mm} \mathrm{H}_{2} \mathrm{O}\right)^{-1}$, respectively. Furthermore, by thermal crosslinking treatment, the filter remained stable in high humidity conditions [13].

Nanoclay is an inexpensive filler used in polymer processing due to its low price, flame retardation and thermo-mechanical properties [16] and has attracted much attention in both industry and academic sectors. The electrospinning of clay polymer has been successfully examined for some polymers, such as poly(methyl methacrylate) (PMMA) [17], cellulose acetate [18], poly(vinylidene fluoride) [19] and polyethylene oxide [20]. Besides the properties mentioned above, the addition of nanoclay to electrospun polymers has also been reported to modify the crystallinity and alignment of the polymer chains $[19,20]$. However, studies on introducing nanoclay into electrospun nanofibers for enhancement of the fibers' roughness for air filtration are lacking, to the authors' knowledge.

In the present study, electrospinning is utilized to make non-woven PVP layers with the potential for air filter applications. The novelty of this work is not limited to the introduction of nanoclay to electrospun fibers for making PVP-nanoclay fiber composites. This strategy can enhance the fiber roughness, fiber size distribution and pore size to improve the required morphology of the air filter application by using inexpensive materials.

\section{Materials and Methods}

The nanoclay used in the experiments was from Sigma-Aldrich, which contained $25 \mathrm{wt} \%$ trimethyl stearyl ammonium. Polyvinylpyrrolidone (PVP), with an average molecular weight of 1,300,000 g/mol, was also from Sigma-Aldrich. The nanoclay was dried at $180{ }^{\circ} \mathrm{C}$ before use in each experiment. A 95\% ethanol from Greenfield Global was used to make the solutions.

PVP-nanoclay solutions were prepared by making sonicated ethanol-nanoclay colloids, adding $10 \mathrm{wt} \%$ PVP to the colloids and stirring for $24 \mathrm{~h}$. Ethanol-nanoclay colloids were made at 3, 10 and 25 weight percent of the PVP (nanoclay:PVP = 3:97, 10:90 and 25:75). Additionally, a plain 10\% PVP solution was used as a reference.

The electrical conductivity of the PVP-nanoclay solutions and ethanol-nanoclay colloids was measured using a conductivity meter with a precision of $0.1 \mu \mathrm{S} / \mathrm{cm}$ at room temperature. Each solution was measured three times, and the average value was reported. 
Electrospinning tests were conducted using a 21-gauge blunt stainless-steel needle at a flow rate of $6 \mu \mathrm{L} / \mathrm{min}$, a voltage of $15 \mathrm{kV}$ and $30 \pm 1 \%$ humidity in a closed chamber. A grounded aluminum rotating drum with a $10 \mathrm{~cm}$ diameter covered by aluminum foil was used as the current collector. The distance between the needle's tip and the drum (working distance) ranged from 10 to $20 \mathrm{~cm}$, and the drum speed was $100 \mathrm{rpm}$ during the electrospinning process.

The produced electrospun fibers were examined using a scanning electron microscope (SEM) equipped with energy dispersive spectroscopy (EDS). An image analyzer (Image J software) was used to measure the fabricated fibers' pore size and fiber size distribution. SEM images from five locations of the samples at 10,000 $\mathrm{X}$ were used for the fiber size measurements for each image analysis. The diameters of the fibers and pores were measured manually using ImageJ software. If a fiber contained beads, the diameter of the uniform section of the fiber was measured.

\section{Results}

Figure 1a shows the SEM image of the as-received nanoclay particles. The nanoclay flakes are agglomerated due to their van der Waals forces. Figure $1 \mathrm{~b}$ is the SEM image of the dried slurry of $3.5 \mathrm{wt} \%$ nanoclay in ethanol after $10 \mathrm{~min}$ of sonication. The sonication process has separated the flakes, but they are reattached after the slurry is dried. It is reported that the ultrasonic treatment can reduce the particle size of the nanoclay suspensions [21].

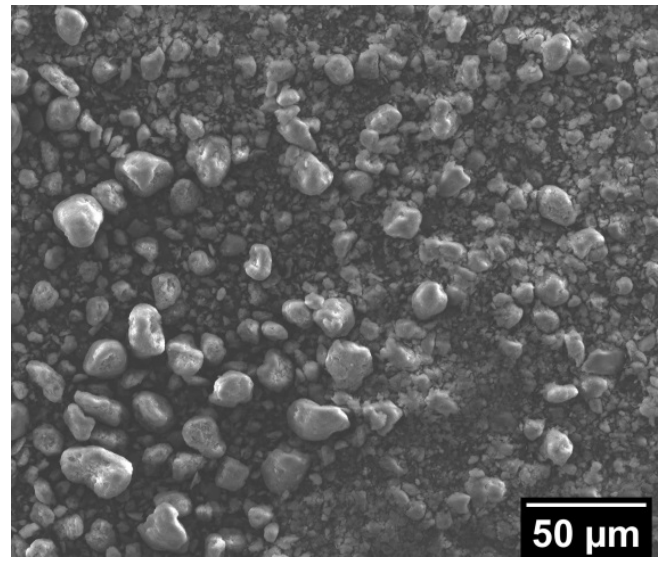

(a)

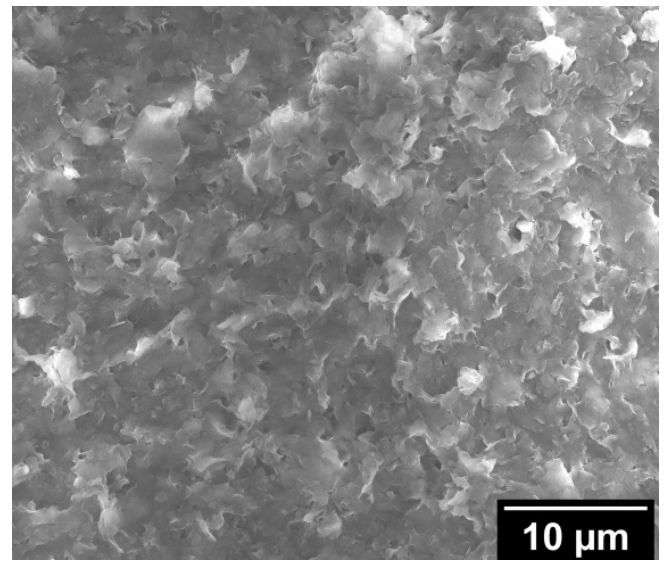

(b)

Figure 1. SEM micrographs of nanoclay; (a) as-received powder; (b) dried slurry $3.5 \mathrm{wt} \%$ nanoclay in ethanol after sonication for $10 \mathrm{~min}$.

Figure 2a is an SEM micrograph of the electrospun plain PVP (without nanoclay), which shows fibers with smooth surfaces. The effect of nanoclay addition on the electrospun fibers' surface morphology is shown in Figure $2 b-d$. As Figure $2 b$ shows, the addition of $3 \mathrm{wt} \%$ nanoclay has a small effect on the fibers' roughness. However, a new set of ultra-fine fibers are formed in the microstructure. At a $10 \mathrm{wt} \%$ nanoclay concentration (Figure 2c), the surface roughness has increased by forming clay-contained beads, and the highest surface roughness is achieved at $25 \mathrm{wt} \%$ concentration (Figure $2 \mathrm{~d}$ ), containing the highest number of clay-contained beads and fibers.

EDS maps of silicon (representing the silicon in the nanoclay) from the SEM images in Figure $3 a, c$ are shown in Figure $3 b$,d, indicating a nonuniform distribution of nanoclay particles in fibers, increasing the fibers' surface roughness. As Figure $3 \mathrm{~b}$ shows, at $25 \mathrm{wt} \%$ nanoclay, larger sections of the electrospun fibers contain nanoclay, compared to $3 \mathrm{wt} \%$ nanoclay (Figure 3d) forming the clay-contained beads. Therefore, the overall roughness of the electrospun fibers at $25 \mathrm{wt} \%$ nanoclay has increased.

Figure $4 \mathrm{~b}-\mathrm{d}$ shows that by adding nanoclay to PVP solution, a new range of ultrafine fibers in the range of $40-200 \mathrm{~nm}$ formed, the range of the fibers' size distribution 
increased up to $100 \%$ and the occurrence of the highest frequency distribution of fiber size shifted from $58.1 \pm 3.1 \%$ for $400-500 \mathrm{~nm}$ fibers to $75.1 \pm 4.3 \%$ for $40-100 \mathrm{~nm}$ fibers. Concurrently, as the nanoclay concentration increased from $3 \mathrm{wt} \%$ to $25 \mathrm{wt} \%$, the frequency distribution decreased dramatically for the larger fiber sizes while increasing sharply for smaller fiber sizes.

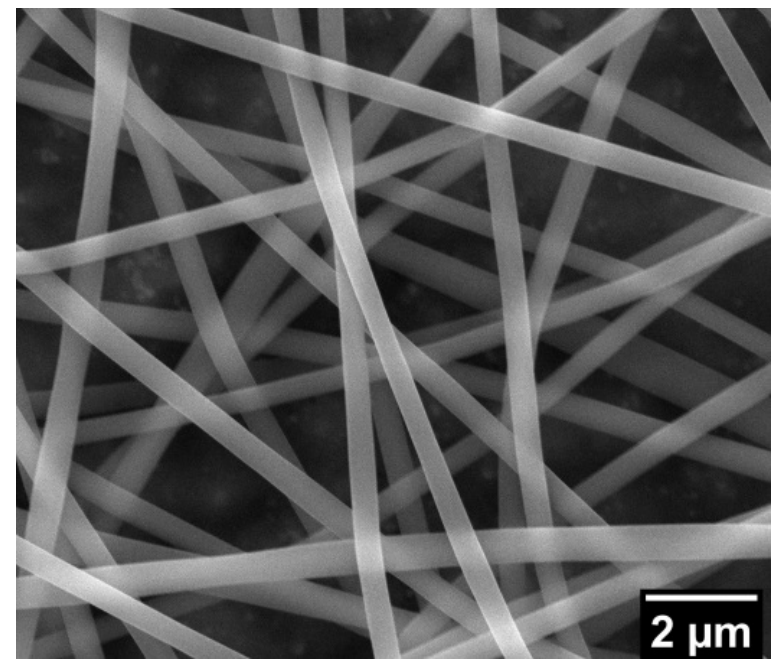

(a)

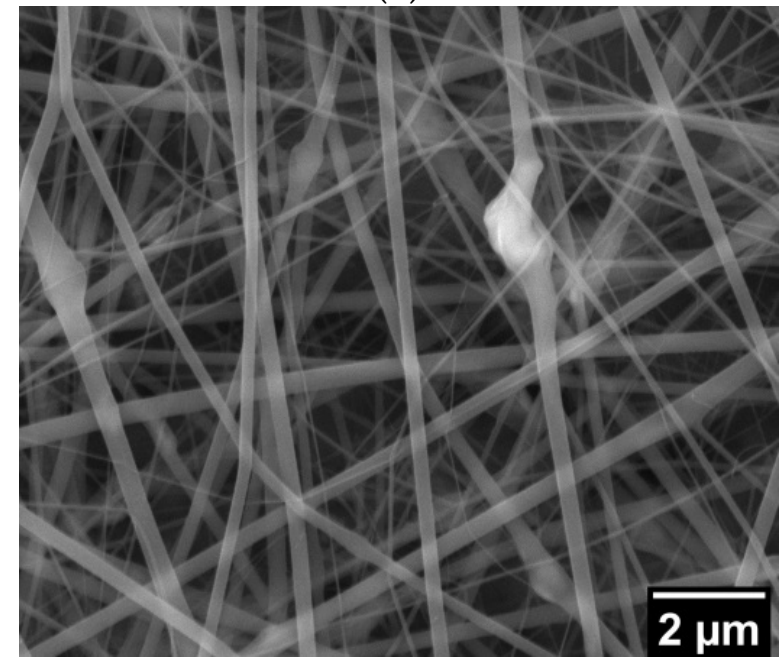

(c)

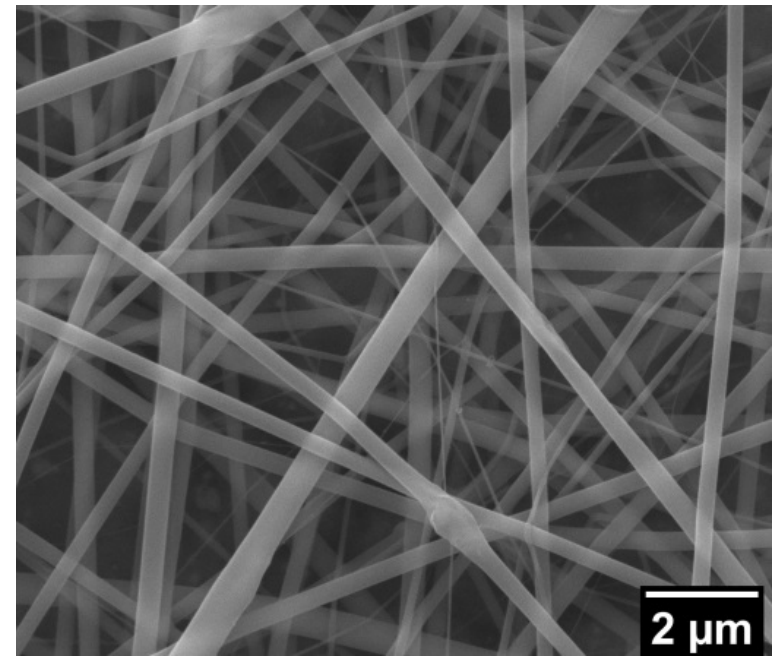

(b)

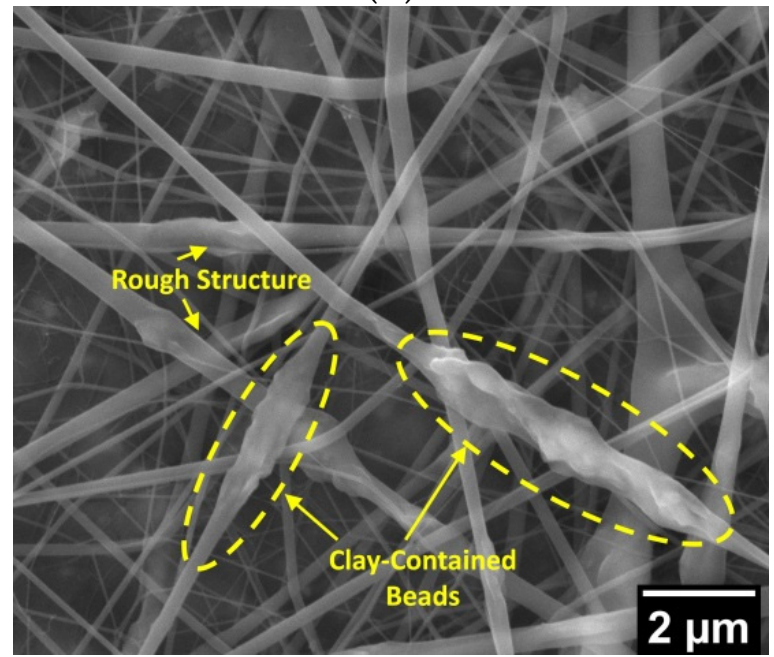

(d)

Figure 2. SEM micrographs of electrospun PVP with different concentration of nanoclay: (a) no nanoclay, (b) $3 \mathrm{wt} \%$ nanoclay, (c) $10 \mathrm{wt} \%$ nanoclay, (d) $25 \mathrm{wt} \%$ nanoclay; the needle tip-collector distance was $10 \mathrm{~cm}$. 


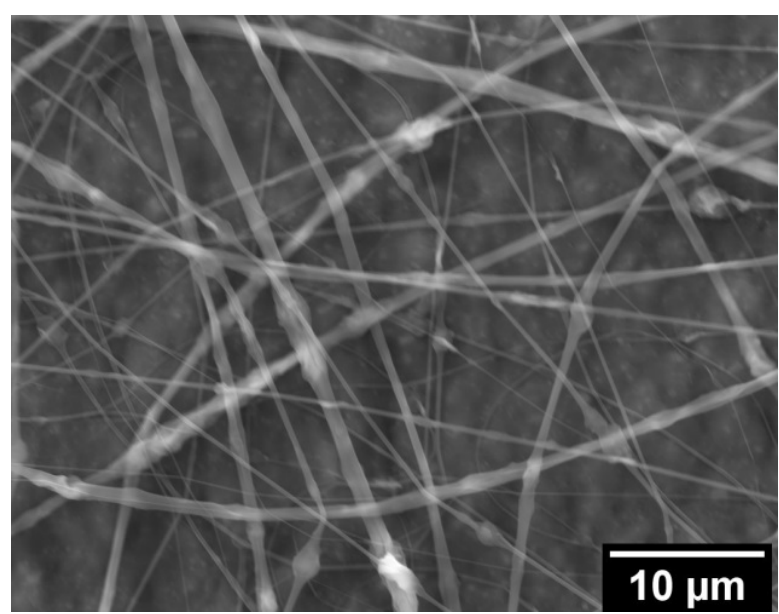

(a)

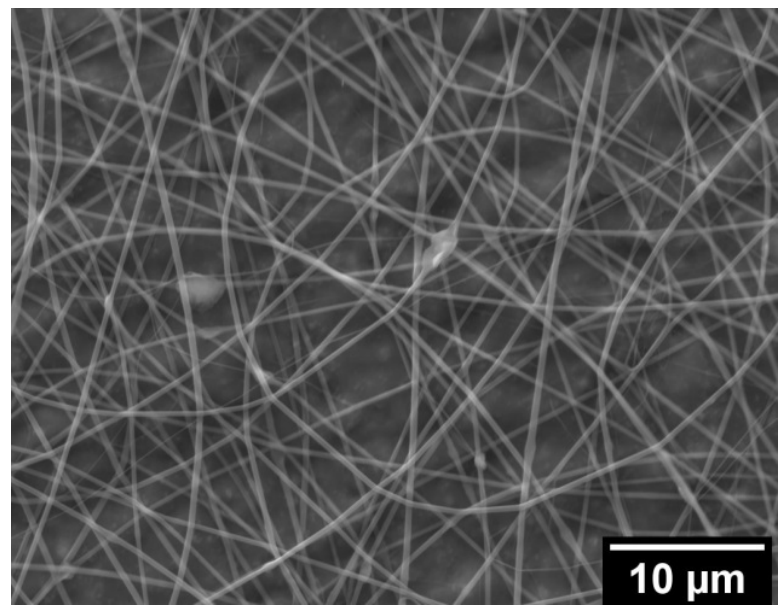

(c)

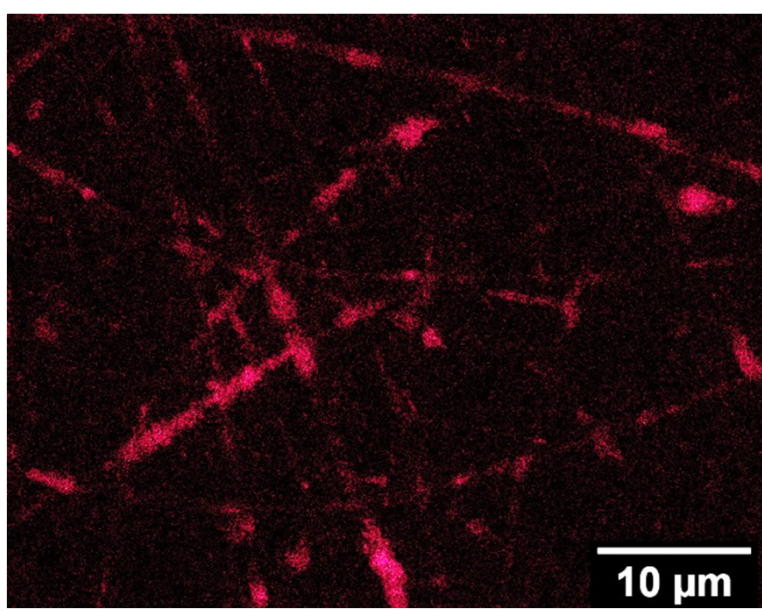

(b)

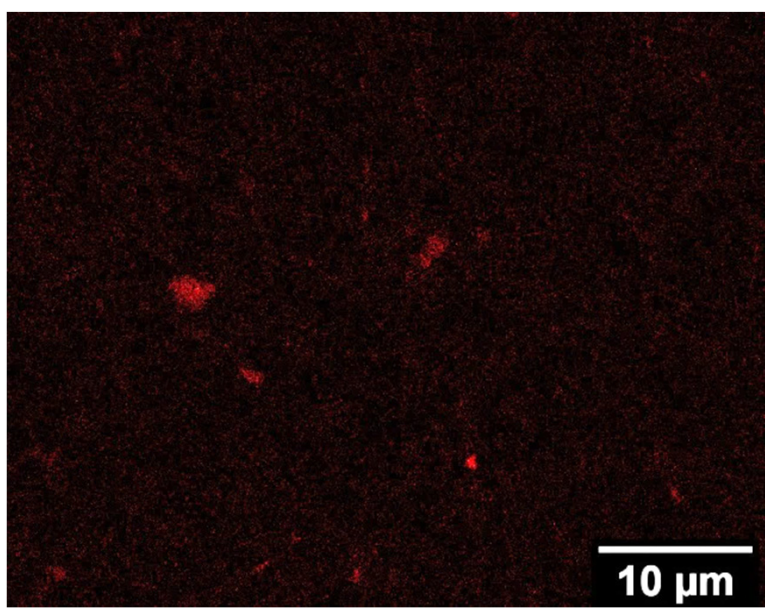

(d)

Figure 3. (a) SEM micrograph of PVP-nanoclay fibers with nanoclay concentration of $25 \mathrm{wt} \%$ and (b) EDS map of (a); (c) SEM micrograph of PVP-nanoclay fibers with clay concentration of $3 \mathrm{wt} \%$ and (d) EDS map of (c); the needle tip-collector distance was $20 \mathrm{~cm}$.

The addition of nanoclay affected the average pore size of the electrospun fiber, too. The effect of the nanoclay addition on the average pore size of the electrospun fibers in Figure 5 shows that adding $3 \mathrm{wt} \%$ nanoclay decreased the average pore size from $1.78 \pm 0.13 \mu \mathrm{m}$ to $0.91 \pm 0.12 \mu \mathrm{m}$; however, a higher nanoclay concentration had less effect on the average pore size, so that at $25 \mathrm{wt} \%$ concentration, the average pore size decreased to $0.65 \pm 0.05 \mu \mathrm{m}$. The effect of nanoclay concentration on the total frequency distribution of the fibers in the range of $40-200 \mathrm{~nm}$, which are formed after nanoclay addition, is shown in Figure $5 \mathrm{~b}$. It shows that at $3 \mathrm{wt} \%$ nanoclay, the total frequency distribution of $40-200 \mathrm{~nm}$ fibers is $71.5 \pm 3.6 \%$ and increases to a maximum of $94.1 \pm 5.8 \%$ at $25 \mathrm{wt} \%$ nanoclay.

Figure 6 shows the effect of nanoclay concentration on the electrical conductivity of the PVP-nanoclay solution and nanoclay colloid. As the nanoclay concentration increases, the conductivity of both solutions increases, but the conductivity of the nanoclay colloid increases at a higher rate. 


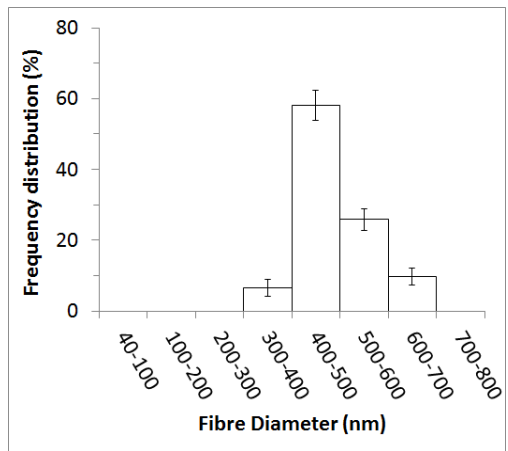

(a)

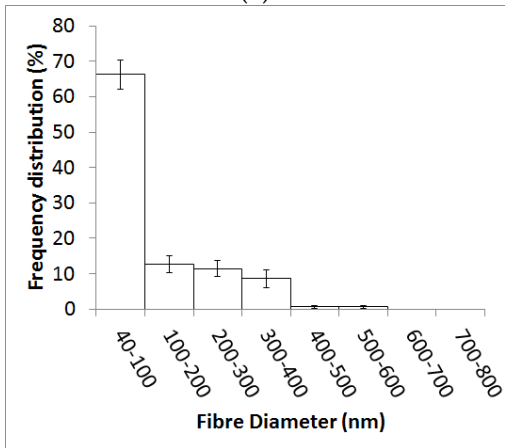

(c)

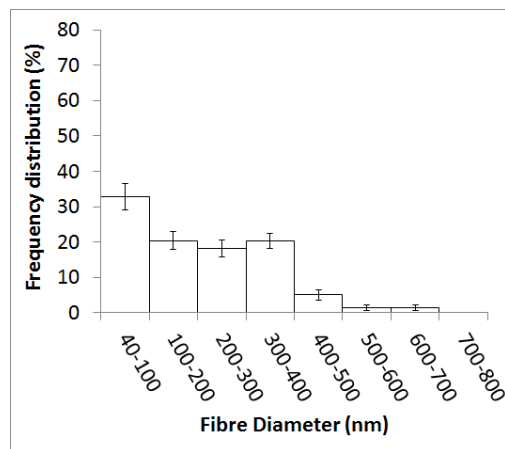

(b)

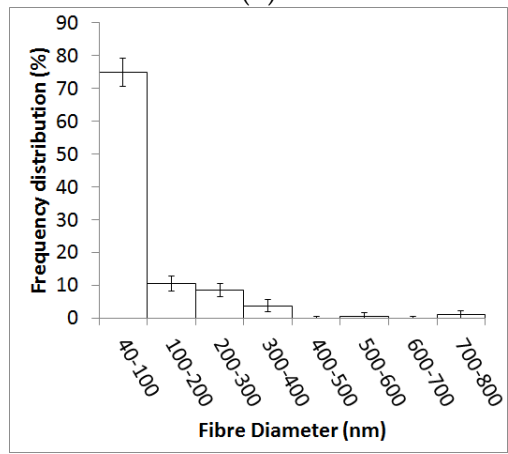

(d)

Figure 4. Fiber size distribution of electrospun PVP with different concentration of nanoclay: (a) no nanoclay, (b) $3 \mathrm{wt} \%$ nanoclay, (c) $10 \mathrm{wt} \%$ nanoclay, (d) $25 \mathrm{wt} \%$ nanoclay.

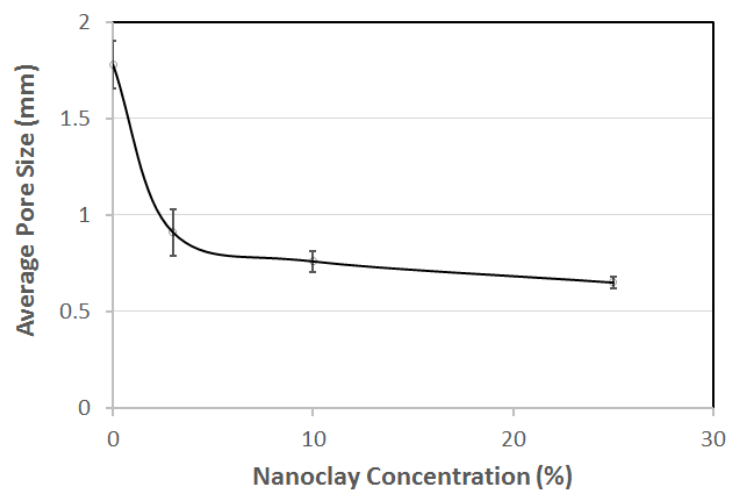

(a)

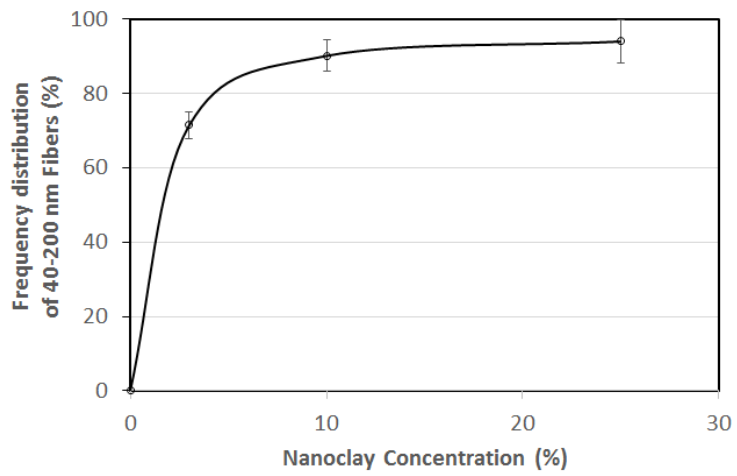

(b)

Figure 5. (a) Effect of nanoclay concentration on the average pore size of the electrospun nanofibers; (b) the effect of nanoclay concentration on the total frequency distribution of the fibers in the range of 40-200 nm. 


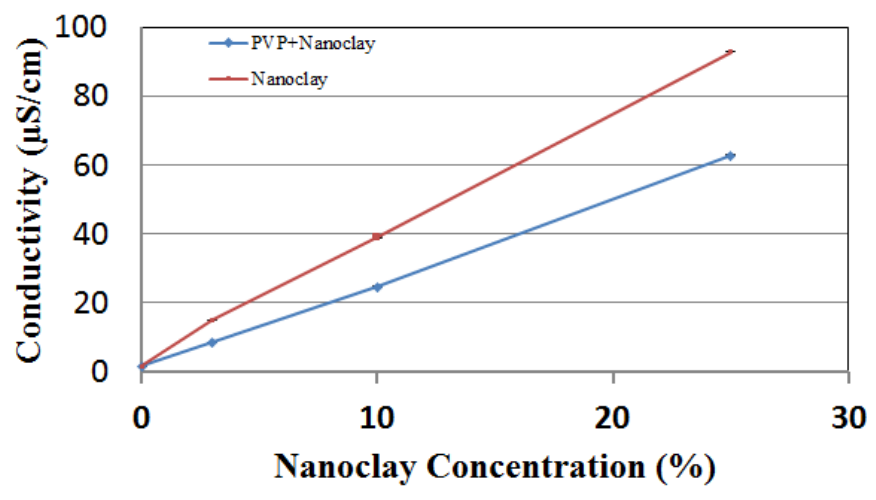

Figure 6. Electrical conductivity of the solution with different clay concentrations.

\section{Discussion}

The main reason for introducing nanoclay to the PVP solutions was to increase the electrospun fibers' surface roughness. It has been reported that the addition of silica nanoparticles to PAN can improve the filtering performance of the electrospun fibers significantly. It was suggested that silica nanoparticles could increase the surface roughness of the fibers. Therefore, stagnated regions (slow air mobility regions) close to the rough sections of fibers can be generated, improving the filtering efficiency while the pressure drop remains low [10]. It was also reported that bead formation could promote the filtering performance because it can optimize the packing density of the fibers, which assists in reducing the pressure drop remarkably, while the filtering efficiency is not deteriorated significantly $[8,22]$.

Figure 2a shows that the plain electrospun PVP fibers had a smooth surface. However, by adding nanoclay to the PVP, the clay-contained beads were formed with a rough appearance in the microstructure. The number of clay-containing beads and their surface roughness increased significantly by increasing the nanoclay concentration from $3 \mathrm{wt} \%$ to $25 \mathrm{wt} \%$ (Figure $2 \mathrm{~b}-\mathrm{d}$ ). It is noteworthy that the nanoclay particles were not very stable in ethanol. However, when PVP was added, it formed a colloidal solution and acted as a dispersant to form metastable suspensions. Although there are many reports on the dispersing effect of PVP on metal oxide nanoparticles [23], very little work has been done on the interaction of clay and PVP [24]. Colloidal solutions containing more than $25 \mathrm{wt} \%$ nanoclay were not used in this work since they needed more than $10 \mathrm{wt} \%$ PVP to be stabilized; however, this concentration of the polymer would be beyond the optimum concentration for electrospinning.

The non-homogeneous distribution of nanoclay particles in the fibers has caused the formation of the silicon-rich beads shown in Figure 3b,d. Comparing the silicon maps in Figure 3b,d with the corresponding SEM images in Figure 3a,c reveals that the clay-containing beads and rough fibers are rich in silicon, indicating nanoclay particle accumulation in those areas.

As Figure 4 shows, adding nanoclay to PVP solutions increased the range of the fiber size distribution and changed the frequency distribution of the fiber size. The histogram in Figure 4a shows that the size of the pure PVP fibers was in the range of 300-700 nm, and most of the fibers had a diameter between 400 and $500 \mathrm{~nm}$. By adding $3 \mathrm{wt} \%$ nanoclay to the PVP solution, ultrafine fibers formed in the microstructure with a broader range of fiber size distribution (40-700 $\mathrm{nm}$ ), while the ultrafine fibers (40-100 nm) showed the highest frequency distribution, as shown in Figure $4 \mathrm{~b}$. Increasing the nanoclay concentration to $10 \mathrm{wt} \%$ and $25 \mathrm{wt} \%$ shifted the highest frequency distribution of fiber size to the ultrafine fibers, as Figure 4c,d shows.

These phenomena can be related to the higher conductivity of the solution at higher nanoclay contents. The conductivity of the PVP-nanoclay solution and nanoclay colloid versus nanoclay concentration in Figure 6 shows that the conductivity increases from $1.70 \pm 0.05 \mu \mathrm{S} / \mathrm{cm}$ for the PVP solution (0.0\% nanoclay) to $62.70 \pm 0.19 \mu \mathrm{S} / \mathrm{cm}$ for the 
PVP-nanoclay solution containing $25 \mathrm{wt} \%$ nanoclay. The PVP-nanoclay solutions show lower conductivity than the nanoclay colloids (without PVP) due to the higher viscosity of PVP-nanoclay solutions, decreasing the diffusion rate of the ions. The PVP-nanoclay solutions show lower conductivity than the nanoclay colloids (without PVP) due to their higher viscosity, decreasing the diffusion rate of the ions. The higher conductivity of the solution makes the electrospinning jet unstable under a strong electrical field. Therefore, a wider range of fiber size distribution can be produced [25].

The effect of the nanoclay addition on the average pore size of the electrospun fibers shown in Figure 5a is mainly due to the formation of finer nanofibers in the presence of the nanoclay. As Figures $2 \mathrm{a}-\mathrm{d}$ and $4 \mathrm{a}-\mathrm{d}$ show, the addition of nanoclay to the PVP solution forms new finer nanofibers in the range of 40-200 $\mathrm{nm}$, which provide a finer nanofiber net and reduce the average pore size. Based on Figure $5 b$, the total frequency distribution of the fibers in the range of $40-200 \mathrm{~nm}$ increases from zero at zero nanoclay to $71.51 \%$ at $3 \mathrm{wt} \%$ nanoclay. However, the rate of increase of the total frequency distribution of $40-200 \mathrm{~nm}$ fibers decreases considerably as nanoclay concentration increases to $10 \mathrm{wt} \%$ and $25 \mathrm{wt} \%$. Therefore, this phenomenon reduces the reduction rate of average pore size at nanoclay concentrations higher than $3 w t \%$, as shown in Figure $5 a$.

A wide range of fiber sizes is beneficial for air filter applications. A combination of thick and narrow fibers enhances the capturing of particles while preventing a highly compact filter structure [9]. Furthermore, the higher surface roughness of the fibers containing nanoclay also improves the filtering efficiency. Therefore, the electrospun fibers containing up to $25 \mathrm{wt} \%$ nanoclay are good candidates for air filter applications.

It should be noted that the hydrophilic nature of PVP had previously restricted its wide application as an air filter. However, crosslinking has proven to increase the stability of PVP at high humidity conditions [13]. Crosslinking forms an integrated network in the polymer by connecting its chains by either intra- or intermolecular covalent or non-covalent links, decreasing the rate of solubility of the PVP fibers. Further research is being performed to investigate the influence of several crosslinking methods and coaxial electrospinning strategies on improving the water resistance of electrospun PVP-nanoclay composites as well as the aerosol filtering performance of the PVP-nanoclay.

\section{Conclusions}

In this study, the effects of 3,10 and $25 \mathrm{wt} \%$ nanoclay addition on PVP electrospun fiber roughness and size distribution were investigated, and the following conclusions were drawn:

1. The addition of 3 to $25 \mathrm{wt} \%$ nanoclay to PVP increased the surface roughness of the electrospun fibers, and 25\% nanoclay concentration provided the highest fiber roughness.

2. Nanoclay additions to PVP solution increased the range of the fibers' size distribution up to $100 \%$. Simultaneously, the highest frequency distribution of fiber size shifted from $58 \%$ for $400-500 \mathrm{~nm}$ fibers to $75 \%$ for $40-100 \mathrm{~nm}$ fibers.

3. As the nanoclay concentration in PVP increased from 3 to $25 \mathrm{wt} \%$, the frequency distribution decreased dramatically for the larger fiber sizes and increased sharply for the thinner fiber sizes.

Author Contributions: Conceptualization, I.A.B. and A.R.R.; methodology, I.A.B. and A.R.R.; software, I.A.B.; validation, I.A.B. and A.R.R.; formal analysis, I.A.B.; investigation, I.A.B.; resources, I.A.B. and A.R.R.; writing-original draft preparation, I.A.B.; writing—review and editing, A.R.R., A.J., M.S., C.B., M.K. and S.S.; project administration, A.R.R.; supervision, A.R.R.; funding acquisition, A.R.R., C.B., M.K. and S.S. All authors have read and agreed to the published version of the manuscript.

Funding: This research was funded by the Natural Sciences and Engineering Research Council of Canada (NSERC) Alliance COVID-19 grant. 
Acknowledgments: Financial support for this research is provided by the Natural Sciences and Engineering Research Council of Canada (NSERC) Alliance COVID-19 grant.

Conflicts of Interest: The authors declare no conflict of interest. The funders had no role in the design of the study; in the collection, analyses, or interpretation of data; in the writing of the manuscript or in the decision to publish the results.

\section{References}

1. Zhu, M.; Han, J.; Wang, F.; Shao, W.; Xiong, R.; Zhang, Q.; Pan, H.; Yang, Y.; Samal, S.K.; Zhang, F.; et al. Electrospun nanofibers membranes for effective air filtration. Macromol. Mater. Eng. 2017, 302, 1600353. [CrossRef]

2. Robert, B.; Nallathambi, G. A concise review on electrospun nanofibers/nanonets for filtration of gaseous and solid constituents (PM2. 5) from polluted air. Colloids Interface Sci. Commun. 2020, 37, 100275. [CrossRef]

3. Mao, N. Nonwoven fabric filters. In Fibrous Filter Media, 1st ed.; Brown, P., Cox, C.L., Eds.; Woodhead Publishing: Cambridge, UK, 2017; pp. 133-171.

4. Haider, A.; Haider, S.; Kang, I.K. A comprehensive review summarizing the effect of electrospinning parameters and potential applications of nanofibers in biomedical and biotechnology. Arab. J. Chem. 2018, 11, 1165-1188. [CrossRef]

5. Reneker, D.H.; Yarin, A.L. Electrospinning jets and polymer nanofibers. Polymer 2008, 49, 2387-2425. [CrossRef]

6. Nam, C.; Lee, S.; Ryu, M.; Lee, J.; Lee, H. Electrospun nanofiber filters for highly efficient PM 2.5 capture. Korean J. Chem. Eng. 2019, 36, 1565-1574. [CrossRef]

7. Zhang, S.; Tang, N.; Cao, L.; Yin, X.; Yu, J.; Ding, B. Highly integrated polysulfone/polyacrylonitrile/polyamide-6 air filter for multilevel physical sieving airborne particles. ACS Appl. Mater. Interfaces 2016, 8, 29062-29072. [CrossRef] [PubMed]

8. Wang, Z.; Zhao, C.; Pan, Z. Porous bead-on-string poly (lactic acid) fibrous membranes for air filtration. J. Colloid Interface Sci. 2015, 441, 121-129. [CrossRef]

9. Dharmanolla, S.; Chase, G.G. Computer program for filter media design optimization. J. Chin. Inst. Chem. Eng. 2008, 39, 161-167. [CrossRef]

10. Wang, N.; Si, Y.; Wang, N.; Sun, G.; El-Newehy, M.; Al-Deyab, S.S.; Ding, B. Multilevel structured polyacrylonitrile/silica nanofibrous membranes for high-performance air filtration. Sep. Purif. Technol. 2014, 126, 44-51. [CrossRef]

11. Jiao, Y.; Liu, Z.; Ding, S.; Li, L.; Zhou, C. Preparation of biodegradable cross-linking agents and application in PVP hydrogel. J. Appl. Polym. Sci. 2006, 101, 1515-1521. [CrossRef]

12. Xie, J.; Mao, H.; Yu, D.G.; Williams, G.R.; Jin, M. Highly stable coated polyvinylpyrrolidone nanofibers prepared using modified coaxial electrospinning. Fibers Polym. 2014, 15, 78-83. [CrossRef]

13. Melike, G.; Calisir, M.D.; Akgul, Y.; Selcuk, S.; Ali, D.; Kilic, A. Submicron aerosol filtration performance of centrifugally spun nanofibrous polyvinylpyrrolidone media. J. Ind. Text. 2021, 50, 1545-1558. [CrossRef]

14. Morozov, V.N.; Mikheev, A.Y. Water-soluble polyvinylpyrrolidone nanofilters manufactured by electrospray-neutralization technique. J. Membr. Sci. 2012, 403, 110-120. [CrossRef]

15. Mikheev, A.Y.; Kanev, I.L.; Morozova, T.Y.; Morozov, V.N. Water-soluble filters from ultra-thin polyvinylpirrolidone nanofibers. J. Membr. Sci. 2013, 448, 151-159. [CrossRef]

16. Bitinis, N.; Hernández, M.; Verdejo, R.; Kenny, J.M.; Lopez-Manchado, M.A. Recent advances in clay/polymer nanocomposites. Adv. Mater. 2011, 23, 5229-5236. [CrossRef] [PubMed]

17. Wang, M.; Yu, J.H.; Hsieh, A.J.; Rutledge, G.C. Effect of tethering chemistry of cationic surfactants on clay exfoliation, electrospinning and diameter of PMMA/clay nanocomposite fibers. Polymer 2010, 51, 6295-6302. [CrossRef]

18. Bazbouz, M.B.; Russell, S.J. Cellulose acetate/sodium-activated natural bentonite clay nanofibres produced by free surface electrospinning. J. Mater. Sci. 2018, 53, 10891-10909. [CrossRef]

19. Neppalli, R.; Wanjale, S.; Birajdar, M.; Causin, V. The effect of clay and of electrospinning on the polymorphism, structure and morphology of poly (vinylidene fluoride). Eur. Polym. J. 2013, 49, 90-99. [CrossRef]

20. Wang, Y.; Li, M.; Rong, J.; Nie, G.; Qiao, J.; Wang, H.; Wu, D.; Su, Z.; Niu, Z.; Huang, Y. Enhanced orientation of PEO polymer chains induced by nanoclays in electrospun PEO/clay composite nanofibers. Colloid Polym. Sci. 2013, 291, 1541-1546. [CrossRef]

21. Cheraghian, G. Synthesis and properties of polyacrylamide by nanoparticles, effect nanoclay on stability polyacrylamide solution Micro Nano Lett. 2017, 12, 40-44. [CrossRef]

22. Yun, K.M.; Suryamas, A.B.; Iskandar, F.; Bao, L.; Niinuma, H.; Okuyama, K. Morphology optimization of polymer nanofiber for applications in aerosol particle filtration. Sep. Purif. Technol. 2010, 75, 340-345. [CrossRef]

23. Koczkur, K.M.; Mourdikoudis, S.; Polavarapu, L.; Skrabalak, S.E. Polyvinylpyrrolidone (PVP) in nanoparticle synthesis. Dalton Trans. 2015, 44, 17883-17905. [CrossRef]

24. Francis, C.W. Adsorption of polyvinylpyrrolidone on reference clay minerals. Soil Sci. 1973, 115, 40-54. [CrossRef]

25. Sill, T.J.; Von Recum, H.A. Electrospinning: Applications in drug delivery and tissue engineering. Biomaterials 2008, 29, 1989-2006. [CrossRef] 